\title{
Drug addicts and their behaviour related to drug addiction among the institutionalized addicts of the Galle District
}

\author{
PV De Silva ${ }^{1}$, P Fonseka ${ }^{2}$ \\ ${ }^{1}$ Lecturer in Community Medicine, Faculty of Medicine, University of Ruhuna, Karapitiya, Galle. \\ ${ }^{2}$ Professor in Community Medicine, Faculty of Medical Sciences, University of Sri Jayewardenepura.
}

\begin{abstract}
Background and Objectives: Drug addiction and rehabilitation of addicts have become a significant public health problem in Sri Lanka. However, relatively few studies have been carried out in drug rehabilitation centres in Sri Lanka. Lack of epidemiological health related data on drug addicts and their behavior related to the drug addiction have further impeded the development and implementation of preventive and health promotive activities targeting this group of people. Therefore, this study was carried out to provide a descriptive overview of drug addicts and their behavior related to drug addiction.
\end{abstract}

Methods: All the drug addicts admitted during a period of three months to the Drug Rehabilitation Centers in the Galle District were included in the study.

An interviewer-administered questionnaire was used to collect the information.

Results: A total of 381 drug addicts participated in the study. Of them, 99\% were males. Mean age of the drug addicts was 34.04 years (SD 7.5). A majority (74\%) were Sinhalese. 94.5\% of addicts had smoked cigarettes before drug addiction and only $5.5 \%$ had started drugs before commencing smoking. A majority $(70.1 \%)$ started using drugs when they were in the age group 10- 20 years. Less than $1 \%$ used the intravenous route. In $88 \%$ of addicts their friends had introduced them to drugs and $74 \%$ initiated taking drugs as an experiment. Most of them (75.8\%) were either self-referrals or referred by family members to the rehabilitation centres. More than $55 \%$ of drug addicts were readmissions. 
Conclusions: In general, adolescent smokers are in a high-risk situation for drug addiction. They should be targeted in preventive and health promotive work. Parents of these adolescents should be more vigilant about the peers of their children since they are the main introducers of victims to drugs. High readmission rate indicates a low success in the rehabilitation process.

\section{Introduction}

Drug addiction was not a major public health or social problem in Sri Lanka until the early 1980s. However, Opium and Cannabis have been used in traditional Ayurvedic medical preparations and possibly also abused since ancient days in Sri Lanka. Written evidence to this abuse was found since the sixteenth century when Portuguese occupied the country ${ }^{1}$. After 1980 , with changes in socio economic policies and the north and east ethnic violence, drug smuggling increased. Drug addiction has now become a significant public health and a social problem in Sri Lanka ${ }^{1}$. Drug addiction is a major problem with increased crime, diseases and poverty among addicts leading to social and family disruption. Globally, $0.4 \%$ deaths and $0.8 \%$ Disability Adjusted Life Years (DALY) are attributed to illicit drug use ${ }^{2}$. In year 2002, $40 \%$ of male prison admissions and $12.5 \%$ of female prison admissions of Sri Lanka were due to narcotic related offences ${ }^{3}$.

Cannabis is the most widely used addictive substance in Sri Lanka. According to National Dangerous Drugs Control Board (NDDCB) and Police Narcotic Bureau there were 200,000 Cannabis users in Sri Lanka in $2001{ }^{4}$.

Heroin, an illegal and highly addictive drug, is the second major addictive substance since 1980 5 . $\mathrm{t}$ is both most abused and most rapidly acting of the opiates and is typically sold as a white or brown powder or as a black sticky substance known on the street as "black tar heroin". According to the NDDCB there were 40,000 50,000 heroin users in Sri Lanka.

Rehabilitation of drug addicts became an urgent need with the increase of drug addiction. To cater to this need, the NDDCB was established in 1984 by parliament act number 11 of 1984 . NDDCB was responsible for implementation of policies and guidelines approved by the government of Sri Lanka in respect of drug law enforcement. The first residential treatment facility for drug addicts in Sri Lanka was declared open by Non Governmental Organization (NGO) Sumithrayo in 1987. Later NDDCB and several other NGOO started residential rehabilitation centres, island wide.

Relatively few studies have been carried out in drug rehabilitation centres in Sri Lanka. Lack of epidemiological health related data on drug addicts in drug rehabilitation centres has further impeded the development and implementation of preventive and health promotive activities targeting this group of people. The main objective of this paper is to provide a descriptive overview of drug addicts and their behavior related to drug addiction.

\section{Materials and methods}

This Study was carried out in all rehabilitation centres for drug addicts in the Galle district. In the Galle district there are four rehabilitation centres for drug addicts located at Unawatuna, Nagoda and Hikkaduwa. One centre at Unawatuna is managed by the NDDCB of Sri Lanka. The other three centres at Nagoda, Hikkaduwa and Unawatuna are managed by the NGO "Nawa Jeewana Amadyapa Hada Sevaya" (NJAHS).

A convenient sample was selected which consisted of all the drug addicts admitted to the rehabilitation centres in the Galle district during a period of three months. Both first admission and readmission addicts were invited to take part in the survey.

\section{Questionnaire}

An interviewer-administrated questionnaire was used to collect information of drug addicts. First part of the questionnaire contained questions related to demographic data including sex, age, ethnicity, religion, marital status, educational status, area of residence, occupation and monthly income. Second parts of the questionnaire contained questions related to drug 
addiction and admission to rehabilitation centres including type of drug, age of addiction, smoking, age of first smoking, introducer to drugs, reason for starting drugs, daily expenditure on drugs, person referred to the rehabilitation centre and number of times admitted to the rehabilitation centres.

The questionnaire was first developed in English, and then translated to Sinhala. The Sinhala version was then back translated to English. The two English versions were compared for consistency. The Sinhala version was used in the study.

The questionnaire was pre-tested among 12 drug addicts admitted to a rehabilitation centre in the Colombo district. Changes were made where necessary to enhance comprehensibility and appropriateness. It was observed that it took 1015 minutes to complete an interview.

The principal investigator and two trained data collectors who are pre-intern medical officers carried out data collection.

The study was carried out with the permission of the Chairman NDDCB and Chairman, NJAHS.

Ethical clearance for the study was obtained from the Ethics Review Committee of the Faculty of Medicine, Galle. The principal investigator coded the data manually. Data processing and analysis was carried out using the statistical software package, EpiInfo-6.

\section{Results}

A total of 385 Drug Addicts had been admitted to the four rehabilitation centres during this period and of them $381(98.96 \%)$ were included in this study. Four refused to participate. Of the participants, 377 (99\%) were males. The age of the addicts ranged from 21 to 60 years with a mean of 34.04 years (SD 7.5). Majority (74\%) of the addicts in the sample were Sinhalese. Burghers accounted for $4.5 \%$ of the sample. The religion of the majority $(55.9 \%)$ was Buddhism while Catholicism was the religion of $33.6 \%$. Of the addicts $51 \%$ were married and $2.2 \%$ were divorced or separated. More than $60 \%$ of drug addicts had education up to $\mathrm{O} / \mathrm{L}$ or above. Only $2 \%$ of addicts had no schooling. $54 \%$ of addicts had an income between
Rs. 7,500.00 - Rs. 15,000.00 per month and $23 \%$ had an income of more than Rs.15,000.00 per month. Approximately $2 / 3$ of the drug addicts were residing in urban areas.

Different behavioral aspects related to drug addiction are presented in Table 1.

Of the interviewed $94.5 \%$ addicts had smoked prior to drug addiction and only 5.5\% had started drugs before starting smoking. Large majority of addicts $(70.1 \%)$ had started to use drugs when their age was $10-20$ years. However, mean age of starting drugs is 20.86 years with standard deviation of 5.80 years. More than $50 \%$ of the addicts had used heroin as their first drug of addiction. Inhalation is the preferred route of administration and less than $1 \%$ had used intravenous route as their main route of administration. All the addicts who used the intravenous route knew the risks of HIV/AIDS and only one-person had shared needles. A large majority of addicts $(88.2 \%)$ had been introduced to drugs by their friends and most of them had used drugs first time to experiment. Most of the drug addicts (75.8\%) were either self-referrals or had been referred by family members. More than 55\% addicts were readmissions.

\section{Discussion}

The survey was carried out among the drug addicts admitted to the rehabilitation centres within three consecutive months. Out of the 385 eligible addicts, 381 participated in the study. Therefore, non-response was just above $1 \%$. Very high male predominance $(99 \%)$ was observed in the study sample. Similar findings were observed in previous surveys carried out in Sri Lanka [3, 6]. According to these findings, female drug addiction in Sri Lanka seems to be minimal. As expected, majority (74\%) of the drug addicts were Sinhalese. However, Burghers (4.5\%) were over represented in the sample. This was a common finding in previous studies too ${ }^{6}$ and they attributed this to the high proportion of Burgers involved in leisure industry in Sri Lanka. Similarly Catholics (33.6\%) were also over represented in the sample. This may be due to the preference of catholic addicts to be admitted to rehabilitation centers managed by NJAHS, a Christian 
Rehabilitation Center for drug addicts in the Galle District. Although family disruption is considered as a reason for starting drugs among drug addicts, only $2.2 \%$ were divorced or separated. Educational level of the dug addicts is fairly high. More than $60 \%$ had studied up to $\mathrm{O} / \mathrm{L}$ or above and only $2 \%$ had never schooled.

Table 1 - Distribution of different behavioral aspects related to drug addiction

\begin{tabular}{|c|c|c|}
\hline Variable & Number & Percentage \\
\hline \multicolumn{3}{|l|}{ Cigarette Smoking status before Drug addiction } \\
\hline Smoked & 360 & 94.5 \\
\hline Not smoked & 21 & 5.5 \\
\hline $\begin{array}{l}\text { Mean duration between initiation of smoking and } \\
\text { drug addiction (months) }\end{array}$ & $\begin{array}{c}61.98 \\
(\mathrm{SD} 16.08)\end{array}$ & \\
\hline \multicolumn{3}{|l|}{ Drug starting age (Years) } \\
\hline $10-20$ & 267 & 70.1 \\
\hline $21-30$ & 87 & 22.8 \\
\hline $31-40$ & 21 & 5.5 \\
\hline$>40$ & 6 & 1.6 \\
\hline \multicolumn{3}{|l|}{ First Drug Addicted } \\
\hline Heroin & 206 & 54.1 \\
\hline Cannabis & 166 & 43.5 \\
\hline Opium & 8 & 2.1 \\
\hline Marijuana & 1 & 0.3 \\
\hline \multicolumn{3}{|l|}{ Main route of administration } \\
\hline Inhalation & 378 & 99.2 \\
\hline Intravenous & 3 & 0.8 \\
\hline \multicolumn{3}{|l|}{ Introducer } \\
\hline Friends & 336 & 88.2 \\
\hline Relatives & 38 & 10.0 \\
\hline Foreigners & 7 & 1.8 \\
\hline \multicolumn{3}{|l|}{ Reason for starting Drugs } \\
\hline Peer pressure & 51 & 13.4 \\
\hline To get rid of stress & 47 & 12.3 \\
\hline To experiment & 283 & 74.3 \\
\hline Mean expenditure for drugs per day & $\begin{array}{l}\text { Rs.951.96 (SD } \\
422.56)\end{array}$ & \\
\hline \multicolumn{3}{|l|}{ Persons who refer them to RCDA } \\
\hline Self referral & 167 & 43.8 \\
\hline Family members & 122 & 32.0 \\
\hline Friends & 74 & 19.4 \\
\hline Law & 6 & 1.6 \\
\hline Clergy & 12 & 3.2 \\
\hline \multicolumn{3}{|l|}{ Admission } \\
\hline First admission & 171 & 44.9 \\
\hline Readmission & 210 & 55.1 \\
\hline
\end{tabular}


Although a large majority of the Sri Lankan population is residing in rural areas, $2 / 3$ of drug addicts were from urban areas. This is a clear indication of high drug addiction rate in urban areas compared to rural areas.

Almost $95 \%$ of drug addicts had smoked tobacco before use the drugs. Mean duration between initiation of smoking and initiation of drug addiction is 61.98 months (SD 16.08). Therefore, smoking is a main risk factor for drug addiction. Most of the drug addicts $(70.1 \%)$ had started using drugs between the ages 10 and 20 years. Majority $(54.1 \%)$ had used heroin as the first drug. However, this may be due to the fact that more heroin addicts wanted to get rid of their habit than users of other drugs thus prompting more of them to get admitted to the rehabilitation centres than users of other drugs. Only less than $1 \%$ of addicts used the intravenous route. Very similar results were found by different surveys in Sri Lanka ${ }^{3}$. All the drug addicts using intravenous drugs found in the present study were aware about the risks of HIV/AIDS due to the contamination of needles. Only one drug addict had occasionally shared needles. Therefore, intravenous drug addiction cannot be considered as a risk factor for HIV/AIDS in Sri Lanka. In contrast in the United States of America (USA) more than 50\% of the persons used the intravenous route ${ }^{7}$.

Most of the addicts (88.2\%) were introduced to drugs by their friends and 3/4 of drug addicts had started to take drugs to experiment. Similar results were found in several studies world wide ${ }^{8}$. Mean expenditure for drugs is Rs.951.96 per day. However, a majority (54\%) of addicts had an income between Rs. 7,500.00 - Rs. 15,000.00 per month. Therefore, their expenditure on drugs cannot be explained by their usual monthly income. Most of the addicts in rehabilitation centres were either self-referrals or had been referred by the family members. None had been referred by health personnel. This is a clear indication of the deficiencies in our public health system, which has not identified drug addiction as a public health problem. Out of the addicts in Rehabilitation Centres, $55.1 \%$ were readmissions. This is an indication of low success of rehabilitation. In contrast, Narconan chain of Rehabilitation Centres in the USA claims to have less than $30 \%$ readmission rate ${ }^{9}$.

In conclusion, urban adolescent smokers are at a higher risk than their rural counterparts for drug addiction. They should be targeted in preventive and health promotive work. Parents of these adolescents should be more vigilant about the peers of their children since they are the main introducers for drug addiction. Public health personnel in the country should also pay more attention to this problem.

\section{References}

1. Jayasooriya DC. The Drug abuse problem in Sri Lanka. Medicine and law 1995; 14: 37-43.

2. World Health Organization. The World Health Report 2002. Reducing Risk Promoting Health life. Geneva, World Health Organization 2002: 66-7.

3. National Dangerous Drugs Control Board, DRUG Abuse Monitoring System, Reporting on Drug users from treatment facilities 2004, NDDCB Colombo.

4. Bureau for international Narcotics and Law enforcement affairs, Narcotic control strategy report 2001, Sri Lanka, Washington DC.

5. INCB (1995). Regional update: South Asia, United Nation Information Services, Vienna; http://www.undep.org/

6. Mendis N. Heroin problem in Sri Lanka a preliminary communication. Journal of the Ceylon College of Physicians 1985; 16: 37-42.

7. INIDA, Cocaine, Marijuana and Heroin abuse up, Methamphamphetamine abuse down: NIDA Notes 2000; 15: 3 .

8. Noi H. Report on result of sociological survey on drug addicts in Vietnam. Ministry of Health, Vietnam 1998.

9. Narconon. Drug addiction Rehabilitation programme. www.heroinaddiction.com, 2005, Oklahoma. 